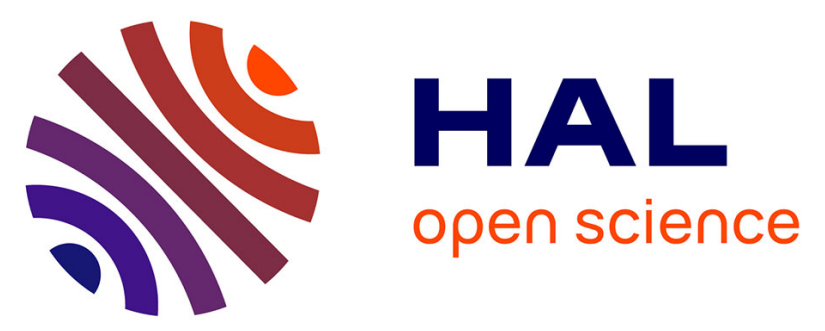

\title{
High temperature gradient nanogap-Pirani micro-sensor with maximum sensitivity around atmospheric pressure
}

Cécile Ghouila-Houri, Abdelkrim Talbi, R. Viard, M. Moutaouekkil, O. Elmazria, Q. Gallas, E. Garnier, A. Merlen, Philippe Pernod

\section{- To cite this version:}

Cécile Ghouila-Houri, Abdelkrim Talbi, R. Viard, M. Moutaouekkil, O. Elmazria, et al.. High temperature gradient nanogap-Pirani micro-sensor with maximum sensitivity around atmospheric pressure. Applied Physics Letters, 2017, 111, pp.113502. 10.1063/1.4995364 . hal-01635348

\author{
HAL Id: hal-01635348 \\ https://hal.science/hal-01635348
}

Submitted on 9 Feb 2018

HAL is a multi-disciplinary open access archive for the deposit and dissemination of scientific research documents, whether they are published or not. The documents may come from teaching and research institutions in France or abroad, or from public or private research centers.
L'archive ouverte pluridisciplinaire HAL, est destinée au dépôt et à la diffusion de documents scientifiques de niveau recherche, publiés ou non, émanant des établissements d'enseignement et de recherche français ou étrangers, des laboratoires publics ou privés. 


\title{
High temperature gradient nanogap-Pirani micro-sensor with a wide dynamic measuring range around atmospheric pressure
}

\author{
C. Ghouila-Houri, ${ }^{1,2, a)}$ A. Talbi, ${ }^{1}$ R. Viard, ${ }^{3}$ M. Moutaouekkil, ${ }^{1}{ }^{4}$ O. Elmazria, ${ }^{4}$ Q. Gallas, ${ }^{2}$ E. Garnier, ${ }^{2}$ A. \\ Merlen, ${ }^{1,2}$ and P. Pernod ${ }^{1}$ \\ ${ }^{1)}$ Univ. Lille, CNRS, Centrale Lille, ISEN, Univ. Valenciennes, UMR 8520 - IEMN / LIA LICS, F-59000 Lille, \\ France \\ 2) ONERA, Chemin de la Hunière 91123 Palaiseau, France \\ ${ }^{3)}$ Fluiditech, Thurmelec, 68840 Pulversheim, France \\ ${ }^{4)}$ Institut Jean Lamour, UMR 7198, Université de Lorraine-CNRS, Vandoeuvre les Nancy, \\ France
}

(Dated: 23 August 2017)

This letter describes and discusses the design and testing of an efficient nanogap Pirani micro-sensor for pressure measurements in a wide range with a maximum sensitivity around atmospheric pressure. The structure combines a substrate-free heated wire and a mechanical support made of silicon oxide micro-bridges allowing both a constant nanoscale gap between the wire and the substrate and a $1 \mathrm{~mm}$ long and $3 \mu \mathrm{m}$ wide wire. The high aspect ratio of wire provides a uniform heating profile along the wire and contributes to low pressure detection. At the opposite, both the nanoscale gap and the short wire length between two micro-bridges contributes to shift the high limit of the pressure range. Tested between $10 \mathrm{kPa}$ and $800 \mathrm{kPa}$, the sensor presents a wide measurement range, not fully reached by the experiments, with a maximum of sensitivity close to the atmospheric pressure and performances with up to $38 \% /$ dec sensitivity when operating in constant temperature mode with an overheat of $20{ }^{\circ} \mathrm{C}$.

Keywords: MEMS pressure sensors; Pirani sensor; Flow control

The knowledge of pressure is very important for many applications in various domains from intra-vascular pressure control and vacuum quality check to flow control on vehicles and theoretical investigations on fluids dynamics $^{1,2}$. The continuous miniaturization of devices by micro- and nano-machining techniques enabled the development of various micro and nano pressure sensors: piezoresistive sensors ${ }^{3,4}$, piezoelectric sensors ${ }^{5,6}$, capacitive sensors $^{7,8}$, optical sensors ${ }^{9-11}$, carbon nanotubes based sensors ${ }^{12-14}$, surface acoustic waves sensors ${ }^{15}$, graphene sensors ${ }^{3,16,17}$ and thermal sensors ${ }^{18-25}$, usually called Pirani sensors. The latter ones present the main characteristic of being non-diaphragm based. Diaphragm-based miniaturized sensors are indeed confronted to physical limits for sensing very small stresses and displacements ${ }^{21}$. Composed of a hot-wire separated from a heatsink by a gap, Pirani sensors exploit the pressure-dependent thermal conductivity of a gas to measure the absolute pressure in an environment, using the thermal exchange between the hot-wire and the gas located in the mentioned gap ga,21,23 $^{2}$. At high pressure, the heat transfer by the collision of gas molecules is fully efficient. When pressure lowers, the mean free path of gas molecules increases and becomes similar to the gap. At this pressure, called pressure of transition, the heat transfer by collision of gas molecules becomes less efficient and the thermal conductivity decreases until the mean free path of the gas molecules is large enough to thermally isolate the wire from the substrate.

\footnotetext{
a)Electronic mail: cecile.ghouila@onera.fr
}

The sizing of Pirani sensors is related to the intended application and depends on two main geometrical parameters: the gap and the wire length. For a given overheat ratio, the pressure of transition is shifted towards higher pressures when the gap decreases. By increasing the wire length, the low pressure sensitivity is increased and the thermal uniformity is improved.

Given that, Pirani sensors are usually divided into two categories $^{20,23}$ : micro-beam structures and resistors on dielectric membrane. Micro-beam structures present a wire resistor fixed at both extremities and suspended over the substrate. The fabrication process and the scaling down are simple, enabling the fabrication of nanowire sensors ${ }^{13,22,24}$. These sensors, with nanoscale gap and microscale length, are suitable for near atmospheric pressure measurements. However, the length is limited due to buckling issues implying that the measurement range is shortened. For resistors on dielectric membranes, a serpentine thermistor, made of metal ${ }^{25}$ or poly-Si ${ }^{23}$, is deposited on a dielectric membrane, suspended over the substrate. These sensors present a higher mechanical toughness against collapse and the increased heat exchange surface improves measurements in the low pressure range. However, the gap, made with back-side bulk machining techniques, is difficult to control and to decrease to nanoscale for measurements within the atmospheric range ${ }^{23}$. These sensors are indeed mostly suitable for low to vacuum pressure measurements in a wide dynamic range.

In this letter, we present a nanogap Pirani sensor demonstrating high sensitive pressure measurements both in a wide range and around atmospheric pressure.

The design, made of a high aspect ratio wire sus- 


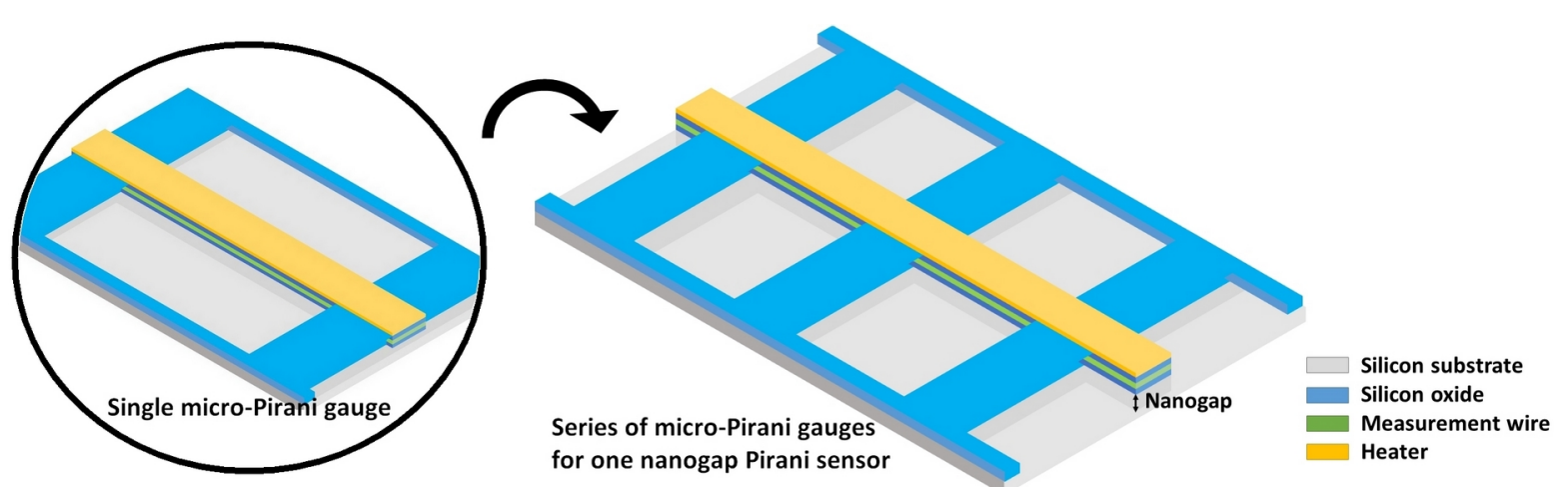

FIG. 1. Schematic of the sensor design

pended over the substrate using perpendicular microbridges for mechanical support, takes advantages from both kinds of usual Pirani sensors. It is structured as an array of micro-Pirani gauges assembled in series (Fig. 1). Each micro-Pirani gauge cell behaves as a micro-beam Pirani sensor: a $3 \mu \mathrm{m}$ wide and $8 \mu \mathrm{m}$ long wire is free from the substrate over a nanoscale gap and anchored on both extremities to perpendicular $2 \mu \mathrm{m}$ wide $\mathrm{SiO}_{2}$ micro-bridges, also separated from the substrate by the gap. The nanoscale gap and the microscale length of the unit cell, provide high pressure measurement and high sensitivity near the atmospheric pressure. The wire is nanostructured with multiple layers, $\mathrm{SiO}_{2} / \mathrm{Ni} / \mathrm{Pt} / \mathrm{Ni} / \mathrm{Pt} / \mathrm{Ni} / \mathrm{SiO}_{2} / \mathrm{Ti} / \mathrm{Au}$, reaching a total thickness beyond $1 \mu \mathrm{m}$. Measurement and heating are uncoupled to improve the signal to noise ratio: the measurement is realized through the $\mathrm{Ni} / \mathrm{Pt}$ multilayer and the heater is composed of Ti/Au (Fig. 1). The $\mathrm{SiO}_{2}$ layers isolate the measurement wire from the heater and strengthen the structure. This single cell structure is duplicated 100 times to reach $1 \mathrm{~mm}$ long. The high aspect ratio of the wire allows a uniform heating profile along the wire and the extended heat exchange area provides sensitivity in the low pressure range. The periodic $\mathrm{SiO}_{2}$ micro-bridges ensure mechanical toughness against collapse, like the membrane in case of resistors on dielectric membrane.

The design results in a structure combining a nanoscale gap, for near atmospheric pressure measurements, a long wire length acting in the low pressure range, and a shorter effective length, engineered with the heat leakage in the bridges, acting the high pressure range and providing a high sensitivity near atmospheric pressure.

The sensor is designed to work in both constant current (CC) and constant temperature (CT) modes. In the CC mode, the pressure is inferred by using the temperaturedependence of the wire resistance. The $\mathrm{Ni} / \mathrm{Pt}$ multilayer (sensitive element) was chosen for its high sensitivity to temperature. In the CT mode, a feedback on the heating current adjusts it to ensure that the temperature along the wire remains constant. The pressure is inferred from the measure of the current variations. The CT mode is more difficult to implement than the conventional CC mode, due to the necessary feedback on the heating current. However, it allows to work at the maximum efficiency at atmospheric pressure, it protects the wire integrity at low pressure, enabling to extend the dynamic range, and, like feedback systems, it increases the resolution and the sensitivity.

We manufactured the micro-sensor using surface micro-machining techniques. Five major CMOScompatible steps ( Fig. 2) are necessary to process simultaneously more than a hundred of sensors on a 3 -inches wafer.
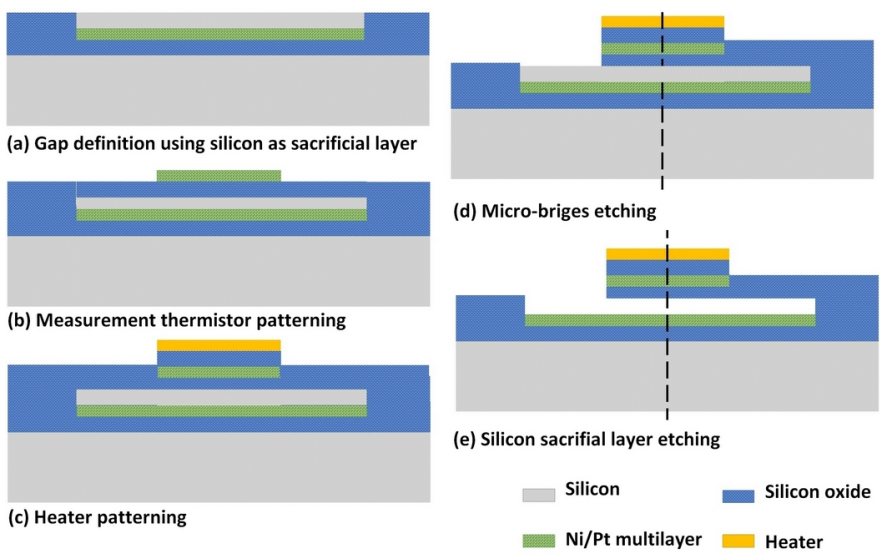

FIG. 2. Micro-machining process of the nanogap Pirani micro-sensor

First, the gap is defined, etching a silicon oxide layer with the Reactive Ion Etching technique and filling with a silicon sacrificial layer deposited using sputtering technique (Fig. 2 (a)). A metallic layer is deposited before this layer to control the gap dimension and stop the sacrificial layer etching. The measurement wire is then patterned using photo-lithography, metal deposition $(\mathrm{Ni} / \mathrm{Pt} / \mathrm{Ni} / \mathrm{Pt} / \mathrm{Ni})$ by evaporation and lift-off techniques (Fig. 2 (b)). After a passivation step, the heater is patterned with the same process (Fig. 2 (c)), except that 


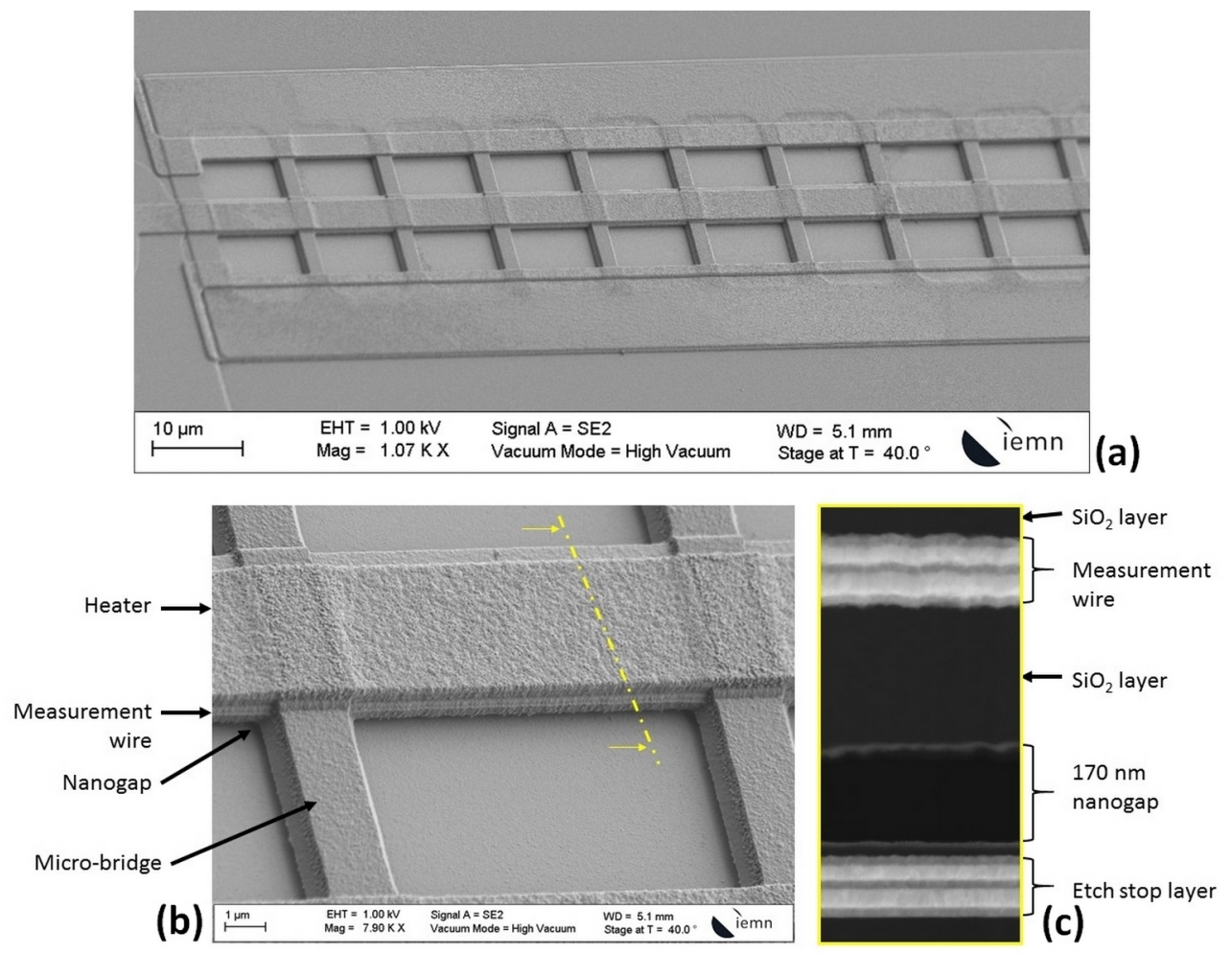

FIG. 3. (a) SEM picture of the manufactured nanogap Pirani micro-sensor (b) Zoom on the suspended wire (c) Cross section SEM picture with zoom on the nanogap

the metallic layers are different $(\mathrm{Ti} / \mathrm{Au})$. Afterwards, the micro-bridges are defined, etching the silicon oxide layers (Fig. 2 (d)). Finally, the sacrificial layer is etched with isotropic XeF2 plasma gas. On Figure 2 (d) and (e), two cross sections are visible, separated by a dotted line: on the left the view without micro-bridge and on the right the view with the micro-bridge. As the structure of the Pirani sensor can be compared to the one of the wall shear stress sensor made earlier ${ }^{26}$, some fabrication steps not detailed here can be found in the corresponding article.

Figures 3 (a) and 3(b) are Scanning Electron Microscopy (SEM) pictures of the manufactured sensors. Figure 3(c) is a cross-section SEM picture allowing a precise measurement of the nanogap of $169 \mathrm{~nm}$. It corresponds to a cross view localized at the yellow dotted line.

Afterwards, we electrically characterized two parameters of the sensors at atmospheric pressure: the temperature coefficient of resistance (TCR)and the temperature elevation with power. The TCR of the Ni/Pt multilayer is measured as $2190 \pm 50 \mathrm{ppm} /{ }^{\circ} \mathrm{C}$ and is indicative of the sensor sensitivity as it directly links the resistance variation of this layer to the temperature variations. The temperature elevation with power, measured as $2.1 \pm 0.2{ }^{\circ} \mathrm{C} / \mathrm{mW}$ (Fig. 4), evaluates the efficiency of the thermal insulation of the device, with a $170 \mathrm{~nm}$ gap separating the wires from the substrate.

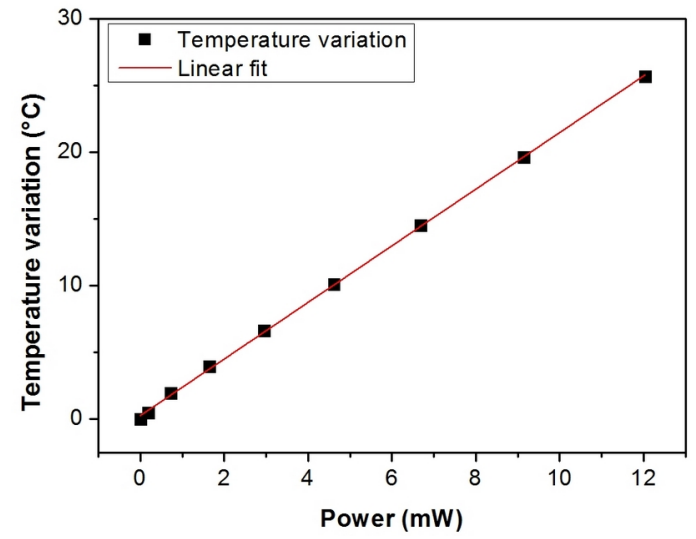

FIG. 4. Electrical characterization of the sensor at atmospheric pressure: temperature variations versus heating power

Finally, the sensor was tested in a pressure-controlled environment, using a PPC4 Fluke Pressure Calibrator, with pressure going from about $10 \mathrm{kPa}$ to $800 \mathrm{kPa}$. The experiments were conducted to evaluate the sensor measurement range in both $\mathrm{CC}$ and $\mathrm{CT}$ modes, and to compare the experimental sensitivities. In CC mode, the sensor is heated with a constant power of $9.5 \mathrm{~mW}$, corresponding to an overheat ratio of $20{ }^{\circ} \mathrm{C}$ at atmospheric pressure. The measured variable is the resistance varia- 

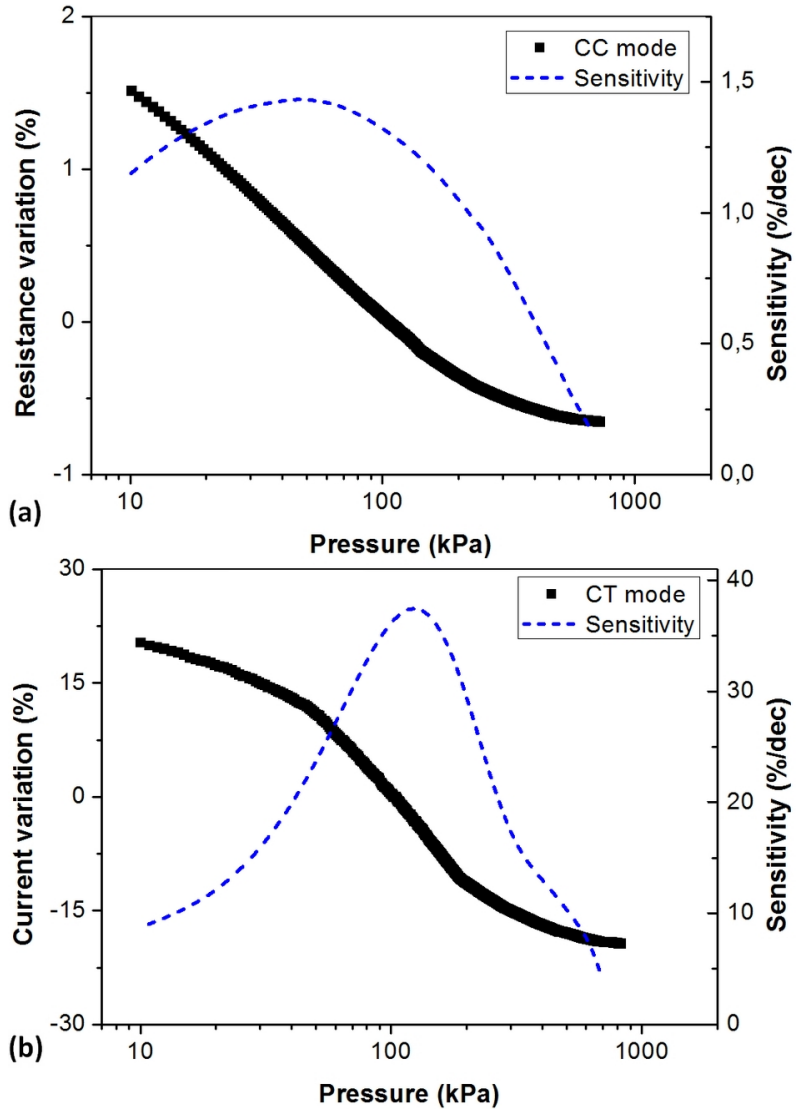

FIG. 5. Nanogap Pirani micro-sensor response to pressure from $10 \mathrm{kPa}$ to $800 \mathrm{kPa}$, when operating in $\mathrm{CC}$ mode (a) and CT mode (b)

tion of the wire. In CT mode, the wire is maintained at constant temperature, with an overheat ratio of $20{ }^{\circ} \mathrm{C}$ and engineered with a feedback on the heating power. The measured variable is the heating current. The results are expressed in Figure 5 (a) and (b), where the sensor response and sensitivity are represented as a function of pressure on about two decades. The resistance variation and the current variation are expressed in \% compared to their value at atmospheric pressure. In CC mode, the sensor exhibits a very large measurement range, covering two decades, including a high sensitivity around atmospheric pressure. The maximum of sensitivity is reached for about $50 \mathrm{kPa}$. On the contrary, the CT mode exhibits a maximum of sensitivity at a higher pressure $(110 \mathrm{kPa})$, closer to the atmospheric pressure. Moreover, it also presents a greatly improved sensitivity up to $38 \%$ /decade. The experiments, conducted between $10 \mathrm{kPa}$ to $800 \mathrm{kPa}$, do not allow to totally reach the saturation regimes of the sensor, neither at low nor at high pressure, meaning that the addressable pressure range is even wider.

As a conclusion, we elaborated an efficient and high sensitive micro-sensor for pressure measurements in a wide range, ranging from $10 \mathrm{kPa}$ to $800 \mathrm{kPa}$, with a great sensitivity around atmospheric pressure. We presented the design (an array of nanogap Pirani gauges arranged in series using a micro-bridges support structure), the fabrication process, the electro-thermal characterizations and the results of experiments conducted in a pressurized environment. The sensor demonstrates a high sensitivity to pressure, with up to $1.45 \% /$ decade in constant current mode and up to $38 \% /$ decade in constant temperature mode. It presents a wide dynamic measuring range around atmospheric pressure, larger than the experimental range that went from $10 \mathrm{kPa}$ to $800 \mathrm{kPa}$. Further work on dynamical characterizations is in progress and will be the subject of a separated work. Micro-machining techniques used to manufacture the sensor, allow low cost fabrication, high volume production and the possibility of on-chip integration.

This work is funded by the French National Research Agency (ANR) in the framework of the ANR ASTRID "CAMELOTT" project. It is supported by the regional platform CONTRAERO in the framework of the CPER ELSAT 2020 project. The authors also thank RENATECH, the French national nanofabrication network, and FEDER.

${ }^{1}$ L. Lofdahl, M. Gad-El-Hak, Progress in Aerospace Sciences, 35, 101-203 (1999).

${ }^{2}$ D. Sparks MEMS for Automotive and Aerospace Applications, 78-105 (2013).

${ }^{3}$ S.-E. Zhu, M. Krishna Ghatkesar, C. Zhang, and G. C. a. M. Janssen Applied Physics Letters, 102, 161904 (2013).

${ }^{4}$ L. Lou, S. Zhang, W.-T. Park, J. M. Tsai, D.-L. Kwong, and C. Lee Journal of Micromechanics and Microengineering, 22, 55012 (2012).

${ }^{5}$ W. Choi, J. Lee, Y. K. Yoo, S. Kang, J. Kim, and J. H. Lee Applied Physics Letters, 104, 123701 (2014).

${ }^{6}$ J. Dzuba, G. Vanko, M. Držík, I. Rýger, V. Kutiš, J. Zehetner, T. Lalinský, Applied Physics Letters, 107,122102 (2015).

${ }^{7}$ H. Vandeparre, D. Watson, and S. P. Lacour Applied Physics Letters, 103 (2013).

${ }^{8}$ A.D. Sundararajan, S.M. Rezaul Hasan Sensors and Actuators A: Physical, 212, (2014).

${ }^{9}$ J. Eom, C.-J. Park, B. H. Lee, J.-H. Lee, I.-B. Kwon, E. Chung Sensors and Actuators A: Physical, 225, (2015).

${ }^{10}$ C. Ghouila-Houri, J.-C. Gerbedoen, R. Viard, A. Talbi, A. Merlen, P. Pernod Procedia Engineering, 120, (2015).

${ }^{11}$ B. McMillen, C. Jewart, M. Buric, and K. P. Chen, Y. Lin, W. $\mathrm{Xu}$ Applied Physics Letters, 87 (2005).

${ }^{12}$ A. S. Chauhan, A. Nogaret, Applied Physics Letters, 102, 233507, (2013).

${ }^{13}$ T. Kawano, H. C. Chiamori, M. Suter, Q. Zhou, B. D. Sosnowchik, and L. Lin, Nano Letters, 7, 3686-3690, (2007).

${ }^{14}$ C. S. Park, B. S. Kang, D. W. Lee, and Y. S. Choi, Applied Physics Letters, 89, 223516, (2006).

${ }^{15}$ P. Nicolay, O. Elmazria, F. Sarry, L. Bouvot, N. Marche, and H. Kambara, Applied Physics Letters, 92, 141909, (2008).

${ }^{16} \mathrm{~J}$. Aguilera-Servin, T. Miao, and M. Bockrath, Applied Physics Letters, 106, 83103, (2008).

${ }^{17}$ R. J. Dolleman, D. Davidovikj, S. J. Cartamil-Bueno, H. S. J. van der Zant, and P. G. Steeneken, Nano Letters, 16, 568-571, (2016).

${ }^{18}$ R. Puers, S. Reyntjens, and D. De Bruyker, Sensors and Actuators A: Physical, 97, 208-214, (2002).

${ }^{19}$ M. Doms, A. Bekesch, and J. Mueller, Journal of Micromechanics and Microengineering, 15, 1504-1510, (2009). 
${ }^{20}$ J. Mitchell, G. R. Lahiji, and K. Najafi, Journal of Microelectromechanical Systems, 17, 93-102, (2008).

${ }^{21}$ K. Khosraviani, A. M. Leung, Journal of Micromechanics and Microengineering, 19, 045007, (2009).

${ }^{22}$ T. Brun, D. Mercier, A. Koumela, C. Marcoux, Duraffourg, Applied Physics Letters, 101, 183506, (2012).

${ }^{23}$ G.-J. Jeon, W. Y. Kim, H. B. Shim, and H. C. Lee, Applied
Physics Letters, 109, 123505, (2016)

${ }^{24}$ G.E. Strelcov, Y. Lilach, and A. Kolmakov, Nano Letters, 9, 2322-2326, (2009).

${ }^{25}$ F. T. Zhang, Z. Tang, J. Yu, and R. C. Jin, Sensors and Actuators A: Physical, 126, 300-305, (2006).

${ }^{26}$ C. Ghouila-Houri, J. Claudel, J-C. Gerbedoen, Q. Gallas, E. Garnier, A. Merlen, R. Viard, A. Talbi, and P. Pernod Applied Physics Letters, 109, 241905, (2016). 